\title{
Museus, hibridação cultural e novas territorialidades ${ }^{1}$ Judite Primo ${ }^{2}$
}

\section{Resumo:}

O texto procura apresentar as relações ente as noções diferenciadas de Estado, ao longo do período moderno e pós-moderno, e o lugar e o papel ocupado pelos museus. Salientar a importância que o contexto político, social, educativo e cultural teve na construção do museu como espaço público na Europa e em consequência na generalidade dos países ocidentais desde a revolução francesa até aos nossos dias. $\mathrm{Na}$ contemporaneidade as noções de património e seus processos, identidade, socialização, teatralização, comunicação e educação fazem parte do universo museológico quer se trate de museus tradicionais quer se trate de museus socialmente comprometidos. Face aos processos de globalização e hibridação cultual, os museus são palcos para as discussões sobre as problemáticas de territorialidade, novas categorias de patrimónios bem como novos entendimentos acerca dos utilizadores/beneficiários da instituição museu.

Palavras Chave: Património; Memória, Hibridação cultural; Sociomuseologia; Politica cultural

\section{Abstract}

The text seeks to present the complex relationships between the different notions of state, along the modern and postmodern period and the place and the role played by museums. Emphasize the importance of the

1 Este texto reproduz partes do sub-capítulo 1.5 da tese de doutoramento «A Museologia e as Políticas Culturais Europeias: 0 Caso Português.», que defendi em Abril de 2007 na Universidade Portucalense - Porto - Portugal.

2 Doutora em Educação e Políticas Culturais, Mestre em Museologia e Graduada em Museologia pela UFBA, atualmente atua como Docente e Diretora do Departamento em Museologia da ULHT Lisboa. 
political, social, educational and cultural context was the construction of the museum as a public space in Europe and consequently in most western countries since the French Revolution to the present day. In contemporary notions of heritage and its processes, identity, socialization, role play, communication and education are part of the museum universe whether traditional museums whether socially committed museums. Given the processes of globalization and cultural hybridization, the museums are scenes for discussions on the issues of territoriality, new categories of assets as well as new understandings of users / beneficiaries of the museum institution.

Key words: Heritage; Memory, cultural hybridization; Sociomuseology; cultural policy

\section{Ponto de partida}

Pretendemos com este texto articular algumas ideias que nos permitem melhor compreender a relação entre a ideia de museus e o contexto sociopolítico em que tomou forma a partir, essencialmente, dos séculos XVIII e XIX.

Não nos parece possível falar da ideia de museus sem evocarmos igualmente a construção das noções de património, articulada com a criação do Estado-Nação Moderno e da sua relação com a expansão colonial.

Quanto a construção do museu contemporâneo, quer se trate de museus tradicionais, quer se trate de museus que se reconhece no cerne da Sociomuseologia, encontramos a ideia de patrimonialização, de cenarização, de teatralização, de socialização das referências de património e memória colectiva no contexto de território de grupos sociais determinados que dão forma à lógica própria dos museus entendidos e assumidos como narradores.

No contexto mais amplo dos processos de globalização a actuação dos museus confronta-se com as questões de hibridação cultural e de construção de novas territorialidades, por isso evocámos os processos de 
urbanização, massificação da cultura, migrações e transnacionalização de bens materiais e simbólicos.

\section{Legitimação pública dos museus e dos patrimónios}

A construção da ideia de Nação, nos séculos XVIII e XIX, envolvendo por um lado a referência a um passado mais ou menos mítico, assenta num novo entendimento e lugar que as ideias de língua, de etnicidade, de tradição ou de religião entre outras assumiam na época.

Todas essas ideias manifestavam-se de forma material através de objectos herdados ou ideias passíveis de serem materializadas, constituindo-se no que poderíamos denominar por entendimento moderno da ideia de património enquanto manifestação identitária. Esse novo olhar sobre o património deu-se por referência ao passado, mas também, por necessidade de estabelecer as diferenças numa Europa de Nações paralela à Europa da expansão colonial.

O interesse pelo património - centrado nas referências da antiguidade clássica e voltado para a criação do nacional - teve como suporte uma nova atitude comparável à existente nos estudos de ciências naturais, onde se reconhecia que era passível de descrição, ou seja, os objectos passaram a ser valorizados independente da sua natureza. Este triunfo da observação apresentava diferentes questões essenciais à construção da ideia de património.

Este processo de construção da noção de património seguiu dois caminhos que se entrecruzavam: o desenvolvimento da ciência fundamentado nos estudos de novas disciplinas (etnolografia, paleontologia, da historiografia moderna, arqueologia) e o caminho da criação de palcos cenários, concebidos como museus públicos, para a apresentação ao maior número possível de pessoas dos estudos, das comparações e das tipologias do saber. 
Esta atitude decorria em simultâneo com a elaboração de esquemas classificatórios sobre a Humanidade. A ideia de Estado-Nação, que ganhou corpus entre a segunda metade do século XVIII e o século XIX, baseando-se no iluminismo, utilizou as grandes colecções reunidas desde 0 Renascimento na Europa e converteu-as em acervos dos primeiros museus públicos, da mesma forma que olhava o mundo através das enciclopédias.

A criação de museus, arquivos e bibliotecas no Estado-Nação tinha o objectivo político de institucionalizar a memória. A organização do Estado-Nação implicava a ideia de construção de códigos comuns que pudessem ser partilhados por todos os elementos de uma sociedade sem distinção de grupos etários, económicos e sociais. A utilização do museu como instrumento público, deve-se ao facto deste servir como um grande palco para a apresentação desses códigos, criados para alimentar a ideia do nacional por oposição ao não nacional.

Assim, no séc. XIX o Estado ligou as tradições formais e informais, políticas e sociais ao assumir um papel protagonista na decisão das actividades que deveriam, ou não, ser fundamentais na vida dos cidadãos. Neste contexto o património desempenhou um papel fundamental $\mathrm{e}$ as instituições a ele vinculadas, em especial os museus, serviram de grandes cenários.

Na primeira metade do séc. XIX a instalação de museus públicos era marcada pela mistura de conceitos que vão desde a ideia de contemplação, de templo de saber, até as de representante do carácter nacional. Sob a égide do nacionalismo foram criados a esmagadora maioria dos museus públicos na Europa oitocentista. A arte, arqueologia, história e etnografia eram entendidas como disciplinas essenciais a serem trabalhadas numa nação moderna e para que a sua divulgação pudesse ser mais expressiva discutia-se 
de que forma os museus públicos poderiam servir de fomento e veículo pedagógico destas disciplinas.

Assim a Europa Nacionalista do século XIX passou a fomentar o aparecimento de museus públicos de arte, arqueologia, antropologia e história. A arte passou a ser utilizada no contexto museológico como símbolo do nacionalismo e da identidade nacional; no mesmo contexto a antropologia e a história foram utilizadas para exaltar os valores tradicionais das nações, aprofundando os estudos sobre a cultura popular e o mundo rural; a arqueologia foi exaltada devido ao crescente interesse pelas antigas civilizações e os museus arqueológicos utilizados como instrumentos para a conservação e estudo dos testemunhos do passado.

Ao longo dos últimos anos do século XVIII e início do século XIX os museus estiveram ligados à ideia de construção do nacional, e referência de memória que fomentava a construção de um novo quadro social. O interesse cultural e científico em relação às colecções converte as instituições em instrumentos indispensáveis de investigação científica, ideia que se concretiza e se reforça ao longo do século XX.

Desta forma, no século XX campo museal foi se ampliado significativamente, amparado por novas noções de património e memória, como também tem representado um importante recurso económico tanto para os grandes centros urbanos, quanto para a sustentabilidade de pequenas comunidades.

\section{A construção do museu contemporâneo}

Ao longo do século $X X$ dois movimentos alteraram essa dinâmica. De um lado, a emergência dos processos globalizantes romperam com as delimitações dos Estadosnação e, por outro, a democratização da educação e do conhecimento possibilitaram o surgimento da força dos 
movimentos sociais e de suas respectivas referências patrimoniais sustentando novos modelos no campo museal.

Tradicionalmente o museu chegou ao século XX como um testemunho fiel da realidade. Para a generalidade das instituições assim definidas, a sua maior virtude era oferecer aos visitantes a totalidade das culturas de uma nação.

Os novos modelos de museus podem ser identificados como aqueles que buscam no alargamento da noção de património o reconhecimento das identidades colectivas localmente. Esses novos museus têm vindo progressivamente a estimular a colectividade na valorização e descodificação dos seus patrimónios e das suas memórias colectivas.

Os novos museus, que têm por função primária o desenvolvimento sustentado das comunidades locais por meio dos trabalhos com o património, tentam romper com a noção do passado como algo estanque e sem vinculação directa com o presente, passando a assegurar procedimentos etnológicos na transmissão dos saberes, das habilidades e do saber fazer.

A questão fundamental no campo da memória colectiva e do seu tratamento pela Museologia é de reconhecermos que ela corresponde apenas a uma maneira possível, dentre outras, de estabelecer espaços de organização e de evocação das referências culturais colectivas ao serviço do conhecimento e desenvolvimento sustentado de sistemas de administração da memória.

O museu foi-se transformando num centro de expressão da dinâmica social dos grupos que trabalhavam a partir da memória e das referências do passado para a construção da sua identidade.

A ideia de um novo tipo de museu, mais socializador e dialógico, torna-se incómoda porque isso implica abolir activa e continuamente os desvios entre a realidade económica e tecnológica e a maneira de pensar e viver essa realidade. 0 
trabalho social ganha nova perspectiva ao se investir na memória do social.

Essa nova Museologia convoca os sujeitos sociais a intervir activamente e a resistir aos determinismos da História dos heróis e do passado glorioso que exclui suas habilidades e seus conhecimentos.

No campo museal a valorização do social mostra-se como forma de supressão de "traumas/recalques culturais», as memórias do social são utilizadas numa perspectiva de transformação de toda a vida presente. Não se trata mais da sistematização estritamente técnica da cultura. Pesquisas e exposições são realizadas a partir do objectivo de tornar actual a vida social, sem perder as suas referências culturais, que é aquilo que a caracteriza. O social passa então a ser priorizado em relação aos conteúdos museológicos, às formas de acessibilidade/metodologias de trabalho e destinatários e/ou participantes do processo museológico.

O novo museu, nas suas diferentes formas e tipologias, ao trabalhar com o social pretende responder aos dilaceramentos da vida cultural e social. O social é então totalmente reinvestido na vida das comunidades, tornando-se o objecto das acções culturais

Não importa discutir o quanto o museu, consciente ou inconscientemente, produz e afirma a ordem estabelecida do presente, importa reconhecê-lo como um aparato ideológico do Estado com funções legitimadoras para proporcionarem diferentes usos da cultura. No entanto é importante reconhecer um outro movimento museológico que segue o caminho do contra-poder, onde mais que buscar legitimar a ordem estabelecida os museus buscam questionar sobre a memória social e os processos de patrimonialização, tornando-se também em instrumento que permitem àqueles que estão preocupados com a construção do presente negociarem e articularem, de forma consciente, uma nova relação com o passado. 


\section{Hibridação cultural}

Uma tendência sobre a construção da identidade nacional chama a atenção para a crise do Estado-Nação como meio de agregação identitária no contexto actual. A noção de "cultura nacional» utilizada como afirmação de uma cultura homogénea dentro dos limites do Estado-Nação, que defende identidades únicas e estáveis, são discriminatórias por serem incapazes de reconhecer a relevância de formas minoritárias e alternativas de expressão cultural no contexto da chamada "cultura nacional».

A identidade nacional, entendida como princípio de uma configuração social imutável e inquestionável (EstadoNação), tende a ignorar a pluralidade identitária que se afirma muito para além dos limites do Estado-Nação. A constatação da crescente diversidade cultural no interior do Estado-Nação fez aumentar a procura pela participação igualitária, pelo reconhecimento de direitos de cidadania e pela maior autonomia por parte das minorias - comunidades - religiosas, regionais, étnicas e outras (Featherstone, 1997).

A identidade pode ser entendida como a fonte de significado e experiência de um povo ou ainda como os elementos que distinguem o "eu» do "outro», «eles» de «nós».

Assim, podemos assumir, que um individuo é detentor de identidades múltiplas e que esta pluralidade é fonte de tensão entre sua auto-representação e acção social, sendo necessário estabelecer a distinção entre identidade e papel social. Os diferentes papeis sociais assumidos pelos indivíduos (p.e.: ser sindicalista, tia, desempregada, jogadora de futebol) são definidos por instituições e organizações existentes na sociedade. A importância, ou não, destes diferentes papeis no comportamento dos indivíduos dependerá de «negociações» e «acordos» entre as organizações e os indivíduos. 
As identidades podem assim ser assumidas como fontes de significados, originadas e construídas pelos actores sociais, através de um processo de individualização. No entanto, não esqueçamos que as identidades também podem ser formadas à partir de instituições dominantes, que vão assumindo tal condição, a medida que os actores sociais a interiorizam e a partir daí constroem o seu significado com base nessa interiorização.

Do ponto de vista social, toda e qualquer identidade é construída. Essa matéria-prima de construção identitária é processada pelos indivíduos, grupos sociais e sociedade, tendo seus significados processados em função de tendências sociais e projectos culturais enraizados na sua estrutura social, bem como na sua visão de tempo e de espaço.

Entender e identificar quem e para que se constrói a identidade colectiva determina os conteúdos simbólicos da identidade e o seu significado para aqueles que com ela se identificam ou dela se excluem.

\section{Novas territorialidade}

As trajectórias dos movimentos urbanos dos anos 80 e 90 podem ser entendidos nos seus entrecruzamentos com as estruturas e instituições políticas, ambientais, culturais e sociais. Os "movimentos urbanos», com seus discursos, actores e organizações, se têm integrado, directa ou indirectamente, nas estruturas dos governos locais. Esta tendência anula o movimento urbano como base de transformação social, e reforça o governo local; os «movimentos urbanos» e suas organizações que defendem o seu território, alimentando as bases de um movimento ambiental influente.

A partir das transformações do mundo contemporâneo resultantes dos processos de urbanização, industrialização e massificação da cultura, migrações e transnacionalização dos bens (materiais e simbólicos), a 
globalização e as formas de integração económica, exigem uma redefinição do conceito de nação. A contemporaneidade e seus contextos pressupõem que as populações consumam informações, entretenimento e alimentos oriundos do estrangeiro; por outro lado os processos migratórios actuais demonstram que grande parte das populações que residem no exterior reproduz a chamada «cultura nacional» e mantém relações com o seu País de origem. Ao mesmo tempo que a comunicação de massa (rádio, televisão, Internet) funciona para trazer, ao consumo interno, informações e códigos de outros povos e de outros territórios, também funcionam como recursos para a documentação e difusão da própria cultura para além das comunidades locais que a geraram.

Esses impactos influenciaram também a dinâmica das acções museais nas suas respectivas interlocuções com a sociedade. Para tanto, abordaremos a seguir alguns aspectos sobre a influência da globalização nas questões patrimoniais e museológicas.

Os valores nacionais veiculados pelos médias são, por vezes, tão importantes e significativos quanto os bens tradicionais, sobretudo se levarmos em conta o seu importante papel em relação à música, ao cinema e à TV na consagração, socialização e renovação de alguns comportamentos.

Ficamos assim com o desafio de entendermos o património cultural de acordo com as condições históricas, sociais, económicas e comunicacionais da contemporaneidade.

Novos movimentos sociais (urbanos e ecológicos) têm vindo a ampliar os debates sobre o património, cultura e participação cidadã e, por isso, provocado um interesse maior sobre a sua preservação.

As mudanças nas formas de produção, na difusão e no consumo das referências culturais implica uma mudança 
na definição de património que se tem vindo a adoptar pelas políticas culturais.

\section{Em tom de conclusão}

É neste contexto que se coloca actualmente o lugar dos museus e da museologia, num quadro social e económico em profunda transformação. Não somente pelas indefinições socio-económicas, mas sobretudo numa tentativa de compreender as diferentes dimensões da globalização, da homogeneização das culturas e da desterritorialização.

Assim, as diferentes percepções e interpretações do processo de globalização cultural não são suficientes para elucidar sobre a essência das relações sociais de poder que norteia tanto a homogeneização como a diferenciação. Sem esse entendimento os dois processos correm o perigo de serem postos no mesmo nível, sem que se reconheça as vinculações e as hierarquias entre ele.

\section{BIBLIOGRAFIA}

Anderson, B. (2005). Comunidades imaginadas: Reflexões sobre a origem e a expansão do nacionalismo. (Col. Perspectiva do Homem). Lisboa: Edições 70. (Edição original, 1983).

Appadurai, A. (2004). Dimensões Culturais da Globalização: A modernidade sem peias. (Col. Teorema Série Especial/ 58). Lisboa: Ed. Teorema. (Edição original 1996)

Canclini, N. G. (1994). O Património e a cultural e a construção imaginária do nacional. In: Revista do património histórico e artístico nacional/ 23, (pp., 95115). Rio de Janeiro: IPHAN.

- (1998). Culturas híbridas: Estratégias para entrar $e$ sair da modernidade. Ensaios LatinoAmericanos/ 1. (2a ed.). São Paulo: EDUS. (Edição original. 1997). 
- (1999). Consumidores e cidadãos: conflitos multiculturais da globalização. (4a Edição, 19 reimpressão). Rio: de Janeiro: ED UFRJ (1a edição 1995).

Castells, M (2003). A era da informação: economia e cultura. (Vol. II: O Poder da Identidade). Lisboa: Fundação Calouste Gulbenkian - Serviço de Educação e Bolsas.

Chagas, M. S. (2002). Memória e poder: dois movimentos. In: Museus e Políticas Culturais, Mário de Souza CHAGAS, \& Myriam Sepúlveda SANTOS, (Orgs.). Cadernos de Sociomuseologia/19, (pp., 35-68). Universidade Lusófona de Humanidades e Tecnologias Centro de Estudos de Sociomuseologia. Lisboa: Edições Lusófona.

Choay, F. (2001). A alegoria do património., São Paulo:

Estação Liberdade e Fundação Editora da UNESP. (Edição original, 1992).

Featherstone, M. (1997). O desmanche da cultura: Globalização, pós-modernismo e identidade. São Paulo: Studio Nobel/ Sesc.

Hobsbawm, E. (1998). A questão do nacionalismo. Nações e nacionalismo desde 1780. (Col. História/ 2). Lisboa: Terramar.

Jeudy, H. P. (1990) Memória do Social. Col. Ensaio \& Teoria. Rio de Janeiro: Forense Universitária.

Meneses, U. B. (1992). O Discurso Museológico: um desafio para os museus. A exposição museológica: reflexão sobre pontos críticos na prática contemporânea.,. In: Ciências em Museus, (pp., 87-105). São Paulo: EDUSP.

Neves, L. (2005) O Programa Operacional da Cultura na Modernização e Dinamização dos Museus Portugueses. Diss. de Mestrado, Lisboa, ULHT

Santos, B. S. (Org.). (2005). Globalização: fatalidade ou utopia? Col. A Sociedade Portuguesa Perante o Desafio da Globalização/ 1. Direcção Boaventura de Sousa Santos. Porto: Afrontamento. (Edição original, 2001). 